\title{
Bio-nanotechnology Approaches to Neural Tissue Engineering
}

\author{
Kun Zhou, David Nisbet, George Thouas, \\ Claude Bernard and John Forsythe \\ Monash University \\ Australia
}

\section{Introduction}

Injury to the peripheral nervous system (PNS) and central nervous system (CNS) may result in severe functional loss. Spontaneous regeneration is limited to small lesions within the injured PNS and is actively suppressed within the CNS. In this chapter we discuss the pathology and changes in the physiological environment following PNS/CNS injury. Several key factors such as the glial scar and inhibitory biomolecules are addressed. Neural tissue engineering approaches attempt to provide an alternative to nerve autografts, and have shown some promising regenerative outcomes. The scaffolds are designed to provide mechanical support for endogenous/transplanted cells at the lesion site, provide guidance cues to neurites and for the attachment or delivery of biomolecules that promote regeneration. Unfortunately many of the current scaffolds used for neural tissue engineering provide only limited regulation of cellular response due to insufficient control of physical support, topological stimulation, degradability and inflammatory/foreign body responses.

Nanostructured materials are currently being investigated for a new generation of neural tissue engineering scaffold. Bio-nanotechnology approaches extend current scaffold strategies for an enhanced manipulation of the physical, biochemical and biological cues that can significantly enhance cell survival and nerve regeneration. Two types of nanofabrication are discussed in this chapter:

(1) electrospinning, which produces nanofibers using a wide range of polymers with controlled fiber diameter, degree of alignment and pore size, and

(2) self-assembled peptide hydrogels which are particularly useful to fill cavities of irregular shape, especially in the case of brain and spinal cord injuries.

In both cases, the nanofibrillar scaffolds mimic some structural features of the extracellular matrix but importantly, the nano-size dimension allows for the high density presentation in three dimensions of peptides and growth factors important for neural repair. Biofunctionalisation strategies will therefore be discussed in some detail. Finally this 
chapter will provide some commentary on the short to long term view on neural tissue engineering and identify some key biological and engineering milestones required for successful nerve regeneration.

\section{Physiological challenges for nerve repair in the PNS \& CNS}

In the United States, approximately 20,000 peripheral nerve injuries required clinical treatment per year (Neville, Huang et al. 2009). Most of the injuries are repaired using nerve autografts, however, autografts are limited to the source of donor nerves and can cause donor site morbidity. Injuries to peripheral nerves cause several deficits including loss of function of the innervated tissue and neuropathic pain. Peripheral nerve injuries are largely induced by trauma resulting from accidents. Peripheral nerves can spontaneously recover from injury when they are not completely severed however in most cases complete nerve transection occurs. After injury, the distal portion of the completely severed nerve begins to degenerate, while the proximal end of the nerve stump swells but undergoes less damage via retrograde degradation. Concurrently, Schwann cells surrounding the axons also degrade. The myelin and axonal debris are phagocytozed by macrophages and Schwann cells followed by regeneration at the proximal end toward the distal stump (Schmidt and Leach 2003). The regenerative outcome depends on the distance and the alignment between the proximal and distal ends. For large defects and non-aligned nerves, structural and functional recovery may not be achieved.

Unlike the PNS, CNS neurons are usually inhibited from regenerating across a lesion site. This inhibition results from a combination of biomechanical and biochemical factors, where healthy adult neurons are actively inhibited from regenerating (Tom, Steinmetz et al. 2004; Zhang, Uchimura et al. 2006; Busch and Silver 2007). The site-specific nature of this inhibition has been demonstrated in the 1980s by a series of experiments showing the failure of PNS axons to lengthen when encountered with CNS glia (David and Aguayo 1981). In the following years, many important inhibitory factors and the associated cell types have been identified at the site of injury following CNS damage. Of the biomechanical inhibitory factors, the major obstacle to regeneration after injury is the formation of a glial scar. Astrocytes undergo a morphological change, extending interwoven processes that lay down a rigid and relatively permanent collagenous scar that physically blocks axonal elongation and reconnection between proximal and distal ends (Fawcett 1997; Fitch and Silver 2008). The problem is compounded as astrocytes up-regulate glycoproteins like tenascin and a number of chondroitin sulphate proteoglycans which play an inhibitory role via growth cone repulsion and inhibition mechanisms to the regenerating neurites (Taylor, Pesheva et al. 1993; Fidler, Schuette et al. 1999; Chan, Roberts et al. 2008). Oligodendrocytes continue to express myelin proteins after injury. Both myelin proteins and myelin debris contain regeneration inhibitors including Nogo-A, myelin oligodendrocyte glycoprotein (MOG) and myelin-associated glycoprotein (MAG), which are the major contributors to the inhibition of axon regeneration post injury (GrandPre, Nakamura et al. 2000; Kottis, Thibault et al. 2002; Filbin 2003; He and Koprivica 2004; Karnezis, Mandemakers et al. 2004).

To date, much of the focus of neural tissue engineering in the CNS has been on curing spinal cord injuries (SCIs). This is largely due to the clearly defined role that scaffolds play in 
restoring neural pathways following SCI. There are about 12,000 new cases of SCI each year in the United States and the number of people with SCI has been estimated to be approximately 255,000. Statistical reports also show that the causes of traumatic SCI are primarily attributed to motor vehicle accidents $(42 \%)$, followed by violence $(15.3 \%)$, falls (27.1\%), and recreational activities (7.4\%) (National Spinal Cord Injury Statistical Center 2009). A recent report released in Australia on behalf of the Victorian Neurotrama Initiative (Access Economics 2009) states that the life time costs of disease and injury to the nervous system is in excess of \$10.5AUD billion per annum, a significant figure for a population less than 25 million. Therefore such injuries are partly responsible for a major economic burden as well as the devastating personal consequences to the patient.

During primary injury of the spinal cord, vascular damage results in microhaemorrhages, which happen within minutes, radiating outward from the central grey matter over several hours. In the case of SCIs, the cord itself can swell significantly to occupy the whole spinal canal at the lesion site, resulting in secondary ischaemia when swelling exceeds venous blood pressure. Ischaemia leads to the release of cytokines and toxic levels of otherwise normally secreted factors from damaged cells, triggering an acute inflammatory cascade that attacks intact neighbouring cells (known as the by-stander effect). Secondary injuries include depolarization of neurons and abnormal release of amino acids. Following ischemia, hypersecretion of factors such as glutamate occurs, resulting in toxic levels in both the injured spinal cord and brain (Dirnagl, Iadecola et al. 1999; Ao, Wang et al. 2007). Excessive levels of this neurotransmitter, secreted from the injured spinal neurons, axons and astrocytes leads to a highly disruptive over-excitation of neighbouring neurons (excitotoxicity). Affected neurons undergo demyelination and increased calcium signalling, triggering apoptotic cascades and oxidative free radical damage. In addition, the humoral pro-inflammatory response of cytokine secretion causes neutrophil and macrophage infiltration into the injury site to ingest bacteria and debris, resulting in edematous cavities (Fitch, Doller et al. 1999).

\section{Current scaffold strategies for new synaptic connections}

\subsection{Nerve guidance conduits}

Gaps and cavities often appear in the injured PNS/CNS, resulting from traumaic injuries or macrophage infltration and post-injury inflammation (Blight 1994; Fitch, Doller et al. 1999). Scaffolds have been implanted or injected into cavities (lesion site) of the injured PNS/CNS normally in the form of conduits with impermeable/permeable walls (Heijke, Klopper et al. 2001; Lundborg, Rosen et al. 2004; Chew, Mi et al. 2007). These materials can be either biologically inert (Lundborg, Dahlin et al. 1991; Zhao, Lundborg et al. 1997; Heijke, Klopper et al. 2001) or biodegradable with a controlled degradation rate (Borkenhagen, Stoll et al. 1998; Xie, Li et al. 2008). Scaffolds are used to bridge or fill the gaps/cavities at the lesion site as well as provide support to surrounding nerve tissue and endogenous/implanted cells. Scaffolds provide adhesion sites to cells, allowing subsequent cell function including proliferation and differentation and even regulate specific cellular behavior by careful manipulation of the dimensional, topograpic and biochemical properties (Corey, Lin et al. 2007; Dodla and Bellamkonda 2008; Christopherson, Song et al. 2009). 
The guidance conduit serves several important roles for nerve regeneration such as:

a) directing axonal sprouting from the regenerating nerve (Tsai, Dalton et al. 2004; Panseri, Cunha et al. 2008),

b) protecting the regenerating nerve by restricting the infiltration of fibrous tissue ( $\mathrm{Li}$ and David 1996; Kitahara, Suzuki et al. 1998; Bundesen, Scheel et al. 2003; Yang, Xu et al. 2004; Lietz, Ullrich et al. 2006; Oh, Kim et al. 2008), and

c) providing a pathway for diffusion of neurotropic and neurotophic factors (Moore, Macsween et al. 2006; Chew, Mi et al. 2007).

Guidance conduites have several advantages over microsurgical autografting, the current gold standard for nerve repair. Suture line tension especially for long nerve gaps $(>5 \mathrm{~mm})$ is ineffective, however regeneration is improved using a guidance conduit (Terzis, Faibisoff et al. 1975; Schmidhammer, Zandieh et al. 2005). The use of donor nerve allografts is less feasible, due to the limited availability of tissue and morbidity following microsurgical procedures. Guidance conduits have therefore received considerable research focus over the past decade.

Early guidance conduits were primarliy made of silicone due to its stability under physiological conditions, biocompatibility, flexibility as well as ease of processing into tubular structures (Zhao, Lundborg et al. 1997; Chen, Hsieh et al. 2000). Although silicone conduits have proven reasonably successful as conduits for small gap lengths in animal models $(<5 \mathrm{~mm}$ ) (Lundborg, Dahlin et al. 1982), the non-biodegradability of silicone conduits has limited its application as a strategy for long-term repair and recovery. Tubes also eventually become encapsulated with fibrous tissue, which leads to nerve compression, requiring additional surgical intevention to remove the tube (Lundborg, Dahlin et al. 1991; Chamberlain, Yannas et al. 1998). Another limiting factor with inert guidance conduits is that they provide little or no nerve regeneration for gap lengths over $10 \mathrm{~mm}$ in the PNS (Lundborg, Dahlin et al. 1982) unless exogenous growth factors are used. In animal studies, biodegradable nerve guidance conduits have provided a feasible alternative, preventing neuroma formation and infiltration of fibrous tissue (Jansen, van der Werff et al. 2004; Oh, Kim et al. 2008). Biodegradable conduits have been fabricated from natural or synthetic materials such as collagen, chitosan and poly-L-lactic acid (Chamberlain, Yannas et al. 1998; Mingyu, Kai et al. 2004; Patel, Vandevord et al. 2008; Ichihara, Inada et al. 2009).

Guidance conduits can be used solely to form an open lumen (Panseri, Cunha et al. 2008), or in combination with molecular and/or biological cues. Open lumina are hypothesized to provide space for linear nerve outgrowth to enable axons to selectively reinnervate the appropriate target. However, a pitfall of an open lumen approach is that it provides limited physical support and can not adequately control the cellular microenvironment. This is due to inadequate sites for cell adhesion and attachment of biological molecules as well as insufficient topological stimulation, which limits the ability of the conduits to encourage cell migration. Therefore, scaffolds are more wildly used in combination with molecular cues to improve nerve regeneration (Labrador, But et al. 1998). Various types of peptides, proteins and polysaccharides, which enhance cell adhesion, proliferation and provide neutrophin support (Lee, Yu et al. 2003), can be used to fill the open lumen (Nakamura, Inada et al. 
2004) or can be blended with the conduit forming material (Mingyu, Kai et al. 2004; Xie, Li et al. 2008). Other cellular cues can also be incorporated using such strategies (Sinis, Schaller et al. 2009). The reconnection of severed nerve axons in the PNS requires appropriate guidance of Schwann cells (Sinis, Schaller et al. 2009). In the case of large gaps between severed proximal and distal axons or severely damaged nerve bundles, guidance conduits with implanted stem/progenitor or supporting cells are essential for axon reconnection (Murakami, Fujimoto et al. 2003; Leaver, Harvey et al. 2006). For instance, conduits seeded with Schwann cells show a comparable effectiveness to autografts in sciatic nerve repair although control conduits with no Schwann cells contained significantly lower densities of nerve fibers, highlighting the importance of cellular biological cues (Neville, Huang et al. 2009).

Experimentally, cell-based therapies using stem and progenitor cell types have led to promising results for the treatment of both PNS and CNS injuries (Lu, Jones et al. 2005; Cummings, Uchida et al. 2006; Deshpande, Kim et al. 2006), with the intention of replacing lost and damaged cells in order to improve endogenous nerve regeneration. While functional recovery at the transplantation site requires cell survival in sufficient numbers, programmed cell death of the transplanted cells invariably occurs due a dearth of appropriate cell-matrix interactions. This has been a major limiting factor in the effectiveness of cell replacement therapies, with some reports of less than $10 \%$ of cells surviving after transplantation (Belle, Caldwell et al. 2004). Scaffolds which provide physical support, controlled degradability, controlled inflammatory/foreign body response and guidance cues must therefore also provide a suitable milieu for the survival and viability of transplanted cells. Unfortunately, current scaffolds for neural tissue engineering do not yet meet all these criteria. However recent progress in nanostructured and biomimetic scaffolds for neural tissue engineering has provided encouraging results, particularly when interfaced with stem cell therapies.

\section{Nanostructured Scaffolds for Neural Tissue Engineering: Fabrication and Design}

The neural architecture of the brain and spinal cord is more complex compared to the PNS, typically organized into discrete three-dimensional (3D) populations, depending on their roles in transmitting and processing signals according to the spatial body plan. At the micro- and nanoscale, cells of the CNS reside within functional microenvironments consisting of physical structures including pores, ridges, and fibers that make up the extracellular matrix (ECM) and plasma membrane cell surfaces of closely apposed neighboring cells (Desai 2000). Cell-cell and cell-matrix interactions contribute to the formation and function of this architecture, dictating signaling and maintenance roles in the adult tissue, based on a complex synergy between biophysical (e.g. contact-mediated signaling, synapse control), and biochemical factors (e.g. nutrient support and inflammatory protection). Neural tissue engineering scaffolds are aimed toward recapitulating some of the 3D biological signaling that is known to be involved in the maintenance of the PNS and CNS and to facilitate proliferation, migration and potentially differentiation during tissue repair. Nanostructured and biofunctional scaffolds are currently being investigated for the provision of microenvironments that are similar to those occurring in vivo, in the 
development of improved cellular function and successful regenerative outcomes (Stevens and George 2005). The scaffold fabrication techniques of electrospinning, self-assembly and phase separation are currently the mainstay of this approach, because they are capable of producing nanoscale (10 to $2000 \mathrm{~nm}$ ) polymer fibers. This chapter will focus on two methods of fabricating nanostructured scaffolds; the "top-down" approach of electrospinning and the "bottom-up" of molecular self-assembly of peptides, both of which have recently received considerable attention in neural tissue engineering.

\subsection{Electrospinning}

Electrospinning was patented by Formhals in 1934 (Formhals 1934) and involves the production of a polymer filament using an electrostatic force. Electrospinning is a versatile technique that enables production of polymer fibers with diameters ranging from a few microns to tens of nanometers. A schematic for an experimental device for electrospinning is outlined in Fig. 1.

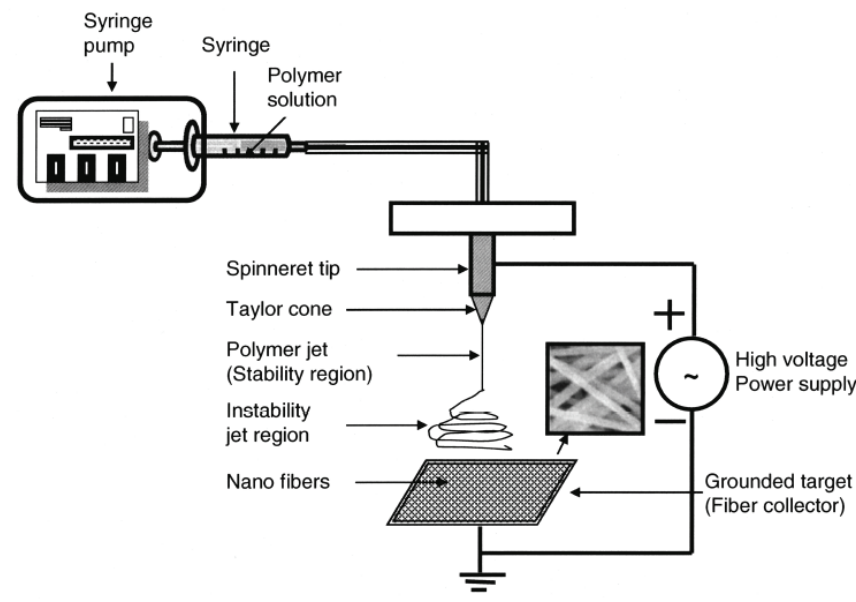

Fig. 1. An electrospinning device with a plate-shape metallic collector. The metallic plate can be either stationary or rotating to achieve different orientations of electrospun nanofibers (Reprinted from Tissue Engineering with permission of Mary Ann Liebert)

Although the electrospinning process is relatively simple in terms of its output, an understanding of the underlying mechanisms and several key processing conditions are essential for effective control of fiber properties. As the polymer solution is pumped to the spinneret tip, the high voltage induces charge accumulation to the solution. The droplet is then elongated into a conical shape, known as a Taylor cone (Taylor 1969) due to the electrostatic repulsive force. Electrospinning is initiated when the repulsive force of the solution exceeds the surface tension of the droplet. A finely charged jet is formed at the tip of the Taylor cone. The jet is then stretched and accelerated, accompanied by solvent evaporation, and eventually collected by the target. Adjustment of the applied DC voltage, feeding rate, polymer solution viscosity and working distance can be used to control the morphology of the collected fibers. Here, some key effects of these processing parameters 
are briefly introduced; for a more detailed review of the electrospinning process the authors direct you to the following reviews (see (Pham, Sharma et al. 2006) and (Boudriot and Wendorff 2006) ). In most cases, increasing the applied DC voltage and resultant electric field will cause greater stretching of the polymer solution, which consequently reduces the diameter of the fibers. However, too high a voltage at a given feed rate will lead to a smaller and less stable Taylor cone, which can cause larger diameter bead formation along the fibers (Zong, Kim et al. 2002; Kim, Kim et al. 2005). The feed rate will also determine the volume of the polymer solution available for electrospinning at the spinneret tip. At a given voltage, higher feed rates generally yield fibers with larger diameters, although these rates are accompanied by slow solvent evaporation during flight time, leading to residual solvent and fusion of fibers. Working distance has less of an influence on fiber morphology, but smaller working distances results in an increased electric field strength and reduced flight time, which may also cause bead formation and fiber fusion.

Of physiological interest is the fabrication of scaffolds with variable fiber orientation and patterning, to create more sophisticated structures that can direct processes like cell migration and neurite outgrowth. A plate-shape metallic collector is often used to collect randomly orientated nanofibers, while aligned nanofibers can be collected by a rapidly rotating cylindrical target (mandrel) with controlled speed to give different degrees of fiber alignment. Alternatively, aligned nanofibers can be obtained between a parallel metallic collector gap, through the modified electrostatic field profile rather than mechanical rotation. The interfiber distance of the electrospun scaffolds can be controlled to some extent by means of adjusting the fiber diameter (Eichhorn and Sampson 2005), rotating speed of the collecting mandrel ( $\mathrm{Zhu}$, Cui et al. 2008), co-electrospinning a soluble or "sacrificial" fiber (Baker, Gee et al. 2008) or by combining with salt leaching (Nam, Huang et al. 2007).

\subsection{Electrospun nanofibrous scaffolds for nerve generation}

Fibers produced by thermal extrusion with diameters in the order of several hundred microns have been used in guidance tubes to provide structural support for cells (Wen and Tresco 2006). However cell orientation, directed process elongation and cell migration are very limited, especially for large diameter fibers of greater than $500 \mu \mathrm{m}$. There is also no appreciable induction of guidance effects on adhered cultured cells (Wen and Tresco 2006). Conversely, neurites follow the long axis of microfibers more obviously when the fiber diameters are in the order of tens of micrometers (Khan, Sayers et al. 1990; Smeal, Rabbitt et al. 2005).

Most cell types can actively sense scale, orientation, texture and stiffness of physical features in their immediate environment, at the microscale (cells and matrix) and nanoscale (macromolecular structures). As the electrospinning technique is capable of providing nanofibers of $10-1000 \mathrm{~nm}$ in diameter with some degree of control over the structural parameters, such as fiber alignment and interfiber distance, it has become a major research focus in neural tissue engineering. The "porosity" of electrospun scaffolds can be up to 70 90\% (Yang, Xu et al. 2004; Gupta, Venugopal et al. 2009) which can facilitate ingrowth and migration of cells, as well as the transportation of nutrients (e.g. metabolites, oxygen) and signaling factors (e.g. growth factors, cytokines). The high surface-to-volume ratio of nanofibrous scaffolds, can provide many more binding sites to cell membrane receptors. This 
can lead to appropriate regulation of gene expression and amplify certain cellular processes. Although the mechanisms of how cells probe and respond to these nanofeatures is still not clear, different topographies of nanofibrous scaffolds have been demonstrated to induce diverse cellular behavior, including cell adhesion, migration (Yang, Xu et al. 2004), orientation (Schnell, Klinkhammer et al. 2007), infiltration and differentiation (Nisbet, Yu et al. 2008).

\section{Nanofibrous scaffolds \& adhesion:}

Electrospun poly(L-lactic acid) (PLLA) nanofibrous scaffolds show significant improvement for neural stem cell adhesion in vitro compared with those cultured on solvent cast flat PLLA surfaces (Yang, Xu et al. 2004). PC12 cells cultured on either flat or nanostructured surfaces in close proximity, migrate from the flat region towards the nanostructured region of the surface (Cecchini, Bumma et al. 2007). A commonly held explanation for the enhanced adhesion is the increase in surface roughness and surface area, leading to an increase in nonspecific protein adsorption and availability of focal adhesion sites (Fan, Cui et al. 2002; Manwaring, Walsh et al. 2004; Yao, O'Brien et al. 2009).

\section{Nanofibrous scaffolds \& stem/progenitor cell differentiation:}

Embryonic stem (ES) cells provide a useful model for therapeutic investigation in tissue engineering due to their ability to give rise to all the main types of adult somatic cells (pluripotency). For the purpose of PNS/CNS regeneration, neural progenitor cells derived from ES cells are typically derived from 4-/4+ retinoic acid induction protocol (Bain, Kitchens et al. 1995). The 4-/4+ induction method avoids the inappropriate differentiation of ES cells within the adult PNS and CNS. During the time that ES cells are cultured as 3D aggregates called embryonic bodies (EBs) they are exposed to retinoic acid, giving rise to the three major types of nerve cells: neurons, astrocytes and oligodendrocytes.

Stem cells cultured in vitro on nanofibrous scaffolds can differentiate in response not only to the soluble differentiation factors, but to the structural features of their surrounding microenvironment. Nanofibrous environments often encourage the differentiation of stem cells and can bias their differentiation toward specific lineages providing enriched populations (Nisbet, Yu et al. 2008). Immunohistochemstry of EBs containing neural progenitor cells established by 4-/4+ induction showed preferential differentiation into neural lineages when cultured on electrospun PCL nanofibers with a mean fiber diameter of $250 \mathrm{~nm}$ (Fig. 2) (Xie, Willerth et al. 2009). About $60 \%$ of the cells within the EBs underwent differentiation when cultured on either aligned or random nanofibers (Xie, Willerth et al. 2009). Significantly lower numbers of glial fibrillary acidic protein (GFAP)-positive cells (astrocytes) were observed on aligned nanofibers compared with those on random nanofibers. Stem/progenitor cells normally show biased differentiation depending on substrate morphology. The majority of the human embryonic stem cells cultured on electrospun polyurethane scaffolds with a mean fiber diameter of $360 \pm 80 \mathrm{~nm}$ differentiate toward neuronal formation, while on 2D flat surfaces, a high proportion of GFAP positive cell types was evident (Carlberg, Axell et al. 2009). Fiber diameter also influences the differentiation of neural stem cells (NSCs) derived from mature CNS lineages (Christopherson, Song et al. 2009). Rat hippocampus-derived adult NSCs show enhanced differentiation on polyethersulfone nanofibrous substrates compared with that on tissue culture plastic (Fig. 3) (Christopherson, Song et al. 2009). However, an increase of oligodendrocytes was evident on smaller diameter fibers $(283 \mathrm{~nm})$, with the highest neuron 
cell number and lowest astrocyte numbers observed on the larger diameter (749 $\mathrm{nm})$ fiber substrates. Cell therapy for spinal cord injuries in animal models using neural progenitors without a scaffold showed $10 \%$ of the transplanted cells becoming neurons, $60 \%$ oligodendrocytes, and about 30\% astrocytes (McDonald, Becker et al. 2004). The intrinsic structural features of electrospun nanofibers, used as a "permanent" stimulus during nerve regeneration, may provide better cues to control cell differentiation compared with cell suspension injections.

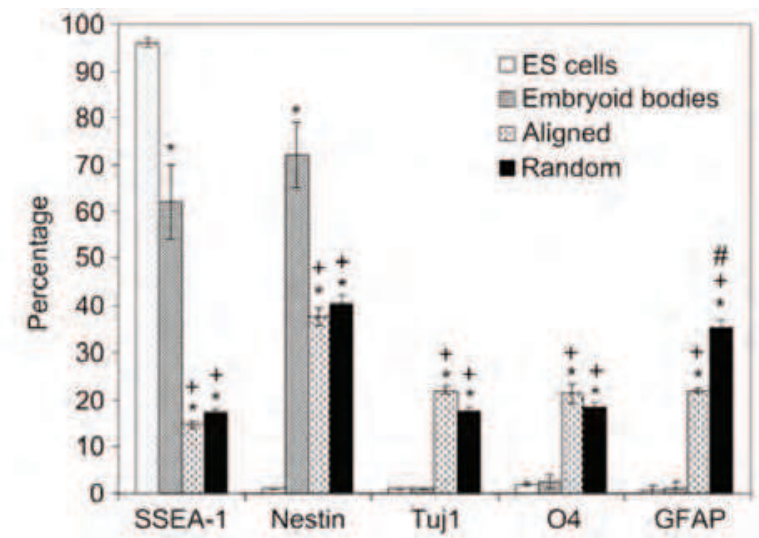

Fig. 2. Immunohistochemstry of ES cells, EBs (treated with by 4-/4+ induction) cultured on tissue culture plates without scaffolds and of EBs (treated with by 4-/4+ induction) cultured on aligned or random PCL nanofibrous scaffolds for 14 days. Cells were stained with SSEA1 for undifferentiated mouse ES cells, Nestin for neural precursor cells, Tuj1 for neuronal cells, O4 for oligodendrocytes, and GFAP for astrocytes. ${ }^{*} \mathrm{p}<0.05$ compared with ES cells. + $\mathrm{p}<0.05$ compared with EBs. \# $\mathrm{p}<0.05$ compared with random PCL nanofibers. (Reprinted from Biomaterials with permission of Elsevier) (Xie, Willerth et al. 2009).

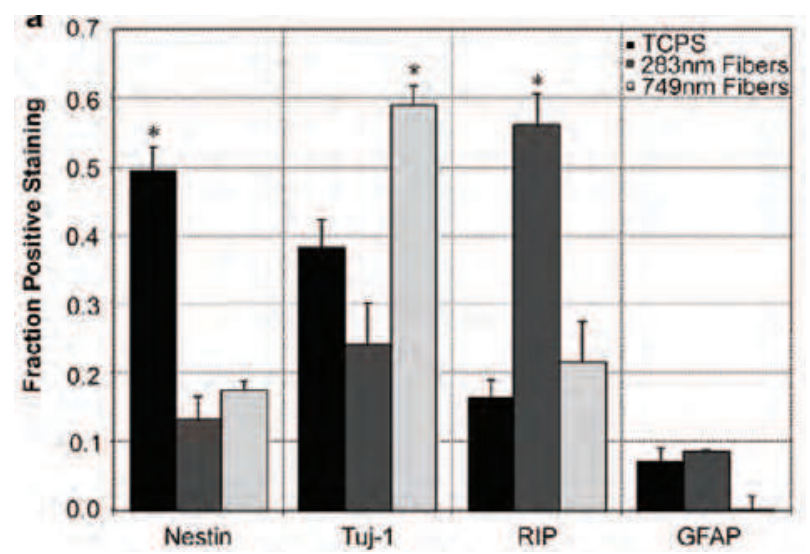

Fig. 3. Immunohistochemstry of rat NSCs cultured on tissue culture polystyrene (TCPS), electrospun polyethersulfone nanofibrous scaffolds with diameters of 283 and $749 \mathrm{~nm}$ respectively in differentiation medium. Cells were stained with Nestin for neural progenitor cells, Tuj-1 for neurons, RIP for oligodendrocytes, GFAP for astrocytes. * $p<0.05$ compared 
with cell staining on the other two culture substrates. (Reprinted from Biomaterials with permission of Elsevier) (Christopherson, Song et al. 2009)

\section{Electrospun nanofibrous scaffolds and contact guidance:}

In repairing intricate neural networks, different kinds of cell types need to be spatially distributed into discrete patterns, with axons precisely guided to their synaptic targets. The way spatial distribution mediates guidance of neurites depends on the following factors inherent to the nanostructured scaffold:

1) physical cues e.g. scaffold fiber dimension, scaffold topography, external stress and stiffness.

2) chemical cues e.g. surface-bound charged molecules and functional groups

3) biological cues e.g. signaling and growth factors and ECM molecules

The topography of the nanofibrous scaffold plays an important guidance role for neurite outgrowth. Primary rat dorsal root ganglia (DRG) cultured on aligned electrospun fibers of acrylonitrile-co-methylacrylate (PAN-MA) (diameter ranged between 400 and $600 \mathrm{~nm}$ ) extend neurites parallel to the fiber direction (Fig. 4) (Kim, Valerie et al. 2008). Neurites extending out from EBs on electrospun poly- $\varepsilon$-caprolactone (PCL) also followed the aligned fiber direction (Xie, Willerth et al. 2009), indicating that cells at different stages can respond similarly to these topographies.

By comparing micro- with nanostructured scaffolds, submicron topography not only causes highly increased non-isotropic differentiation but also significantly influences the contact guidance cues for PC12 and substantia nigra cells (Manwaring, Walsh et al. 2004; Cecchini, Bumma et al. 2007). However, nanoscale features may only exert contact guidance cues within a certain window of nanodimensions (Manwaring, Walsh et al. 2004; Foley, Grunwald et al. 2005). Neurites on aligned fibers are significantly longer than that on randomly aligned fibers (Corey, Lin et al. 2007; Xie, Willerth et al. 2009; Yao, O'Brien et al. 2009), and this increase in length is also associated with changes in the polarity of individual cells due to re-organization of cytoskeletal components. Similar changes in cell structure are responsible for the elongated morphology of the cell body and neurite outgrowth for PC12 cells, human embryonic stem cells and neuroblastoma cells (Corey, Lin et al. 2007; Gerecht, Bettinger et al. 2007; Ferrari, Cecchini et al. 2009). Specifically, cytoskeletal filaments including vimentin, a-tubulin and calponin align in the same axis as the topographic nanoscale feature (Gerecht, Bettinger et al. 2007), with a reversal of filament alignment in response to treatment with actin polarization disrupters. However, the precise sequence of cytoskeletal events in association with the observed contact guidance remains unclear (Cecchini, Bumma et al. 2007). 

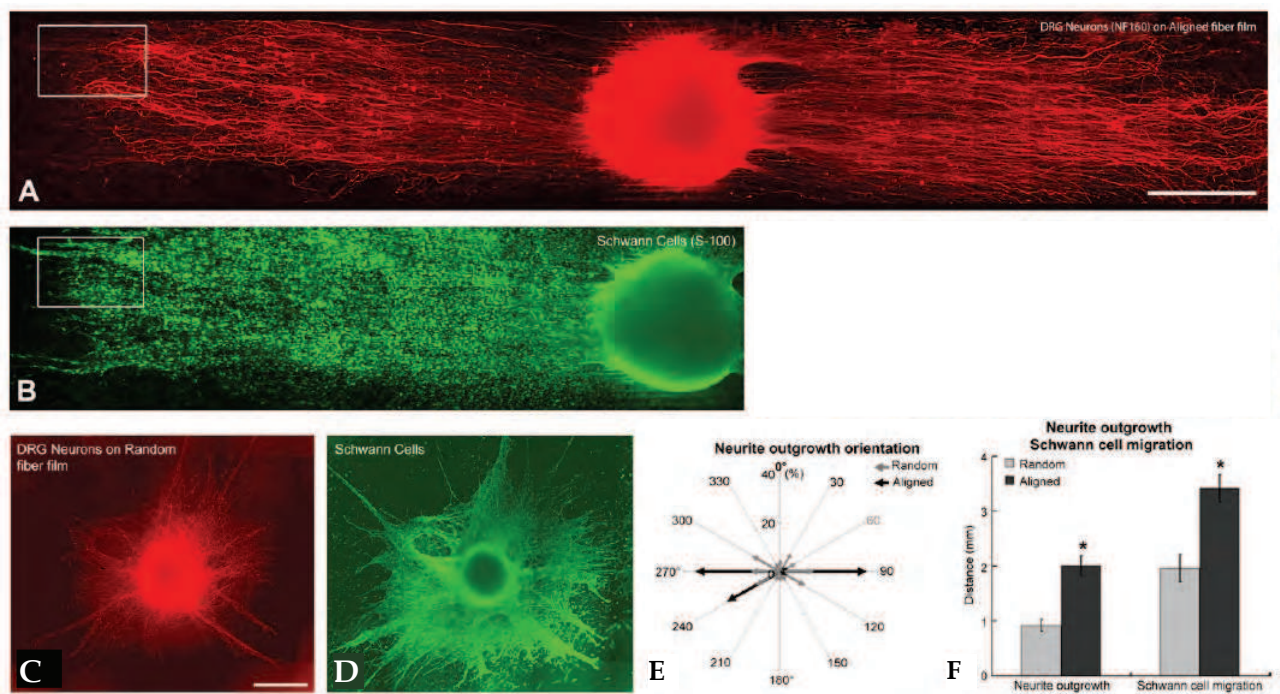

Fig. 4. Contact guidance role of aligned electrospun PAN-MA nanofibers of neurites extending from cultured DRG explants: (A) neurites extended parallel to aligned fibers, stained by NF160 for axons. (B) Schwann cell migration along aligned fibers, stained by S100. (C, D) Random outgrowth of DRG neurites on random fibers, stained by NF160 and S100 respectively. (E) Quantitative comparison of neurite outgrowth on aligned and random fibers, arrows indicate neurite extending direction, arrow length indicates the possibility of growth in that direction. (F) Quantitative comparison of neurite outgrowth length and Schwann cell migration on random and aligned fibers. ${ }^{*} \mathrm{p}<0.05$, error bar stands for standard error of mean (Reprinted from Biomaterials with permission of Elsevier) (Kim, Haftel et al. 2008).

In addition to topographical cues on neurite guidance, chemical cues, in many cases, are just as critical for nerve regeneration. After PNS/CNS injury, the secreted growth factors are normally at sub-optimal levels, and aligned nanofibrous scaffolds can potentially encourage neuritogenesis in cooperation with growth factors, especially for fibers with diameters less than $400 \mathrm{~nm}$ (Foley, Grunwald et al. 2005). Collectively, the alignment of nanofibrous scaffolds could potentially provide a better approach to PNS and CNS repair when bridging long gaps across a lesion site.

\section{Building Biofunctionality into Electrospun Nanofibers:}

Synthetic polymeric materials are widely used due to their superior mechanical properties and ease of electrospinning. At present, many of these biodegradable polymers have limited interaction with cells, relying largely on non-specific adsorption of proteins and the subsequent interaction with cell membrane processes and receptors which may give mixed and unwanted signaling (Cecchini, Bumma et al. 2007). The challenge remains to produce nanofibers with more bioactive surfaces, significantly improving specific targeting of cellsubstrate interactions and consequently creating a more biomimetic microenvironment for implanted cells. There are several methods to improve bioactivity of nanofibrous scaffolds: 
1) Polymer blending

Synthetic polymers can be blended with naturally derived biopolymers and ECM components such as hyaluronic acid (Ji, Ghosh et al. 2006) and collagen (Schnell, Klinkhammer et al. 2007; Jose, Thomas et al. 2009). Some of these polymers normally have specific biomolecular interactions at the cell surface to elicit specific responses and phenotypic changes, however the biomolecules themselves are limited in terms of practicality by their poor mechanical properties and formability. It is possible to fabricate electrospun scaffolds from blends of synthetic and natural polymers, which will then have improved cell-substrate interactions. Collagen for example, is the prevalent structural protein of the ECM, however it is relatively unstable due to the low fiber strength to withstand long-term support for cell adhesion and rapid enzymatic degradation (Okada, Hayashi et al. 1992). It should be noted that collagen denatures into gelatin when being electropun from fluoroalcohol solvents, therefore losing some of its ECM function (Zeugolis, Khew et al. 2008). However, using a mixture of phosphate-buffered saline and ethanol as solvent can avoid denaturing of collagen during the electrospinning process (Dong, Arnoult et al. 2009). Blending collagen with synthetic polymers has also assisted in overcoming these issues. The orientation of neurites from chick embryonic DRG is enhanced on aligned blended polycaprolactone/collagen (72:25) nanofibers compared with that on aligned, pure PCL (Fig. 5) (Schnell, Klinkhammer et al. 2007). Meanwhile, strong fasciculation of axons occurred on PCL nanofibers, which may suggest stronger axon-axon interactions in preference to axon-substrate interactions. The migration and proliferation of Schwann cells is also significantly improved on aligned PCL/collagen nanofibers, indicating more specific biomolecular interactions between cells and the collagen polymers on the nanofiber surface (Geiger, Bershadsky et al. 2001).

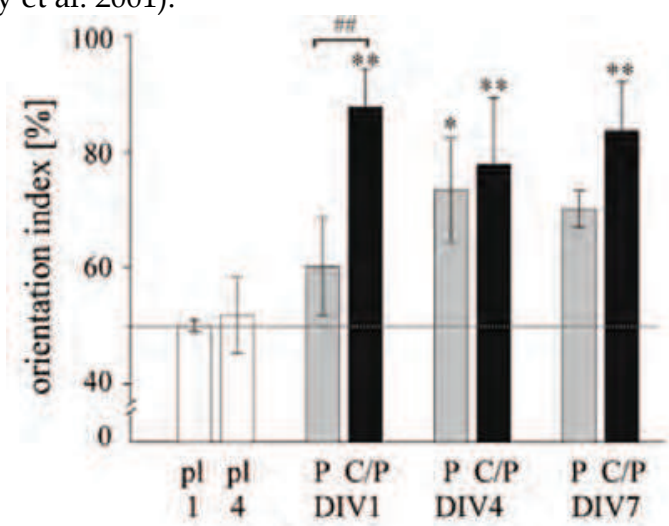

Fig. 5. Orientation of neurites extending from DRG explants on polylysine coated coverslips $(\mathrm{pl})$, aligned PCL electrospun nanofibers $(\mathrm{P})$, aligned collagen/PCL co-electrospun nanofibers $(\mathrm{C} / \mathrm{P})$, measured on 1,4 and 7 days in vitro (DIV). The horizontal dotline $(50 \%$ orientation index) indicates random alignment of neurites, $0 \%$ and $100 \%$ orientation index represent perpendicular and complete alignment respectively. ${ }^{*} p<0.05,{ }^{* *} p<0.01$ compared with random alignment, $\# \# \mathrm{p}<0.01$ between $\mathrm{P}$ and $\mathrm{C} / \mathrm{P}$ at 1 day in vitro, error bars indicate standard error of the mean. (Reprinted from Biomaterials with permission of Elsevier) (Schnell, Klinkhammer et al. 2007). 
2) Surface biofunctionalization

Although naturally derived polymers like collagen can be electrospun together with synthetic polymers to provide biomemitic nanofibrous scaffolds described previously, the concentration of the biological polymer in the blend is variable and limited in order to maintain desirable mechanical strength, diameter and orientated structure (Kwon and Matsuda 2005; Schnell, Klinkhammer et al. 2007). The bioactivity of the biological molecule in the blend largely depends on its degree of migration to the nanofiber surface where it is exposed to cells (Kwon and Matsuda 2005). Furthermore, low molecular weight molecules are difficult to be processed via electrospinning since a sufficient molecular weight is generally required to provide viscosities for stable fiber formation. However, specific peptide motifs derived from fibronectin and collagen VI have been identified to play an important role in nerve regeneration such as encouraging sprouting of hippocampal mouse neurons (Schense, Bloch et al. 2000), and these motifs are only short fragments of up to six amino acids. Therefore, immobilization of these molecules to the synthetic nanofiber surface provides an alternative method to render the fibers bioactive. Low molecular weight biological molecules can be covalently cross-linked to the surface, provided the surfaces are suitably functionalized for crosslinking, otherwise, pre-chemical treatment is required. The type and density of functional groups available for crosslinking will determine the degree of functionalization and subsequent bioactivity of the scaffold. Polyamine nanofibers with surface immobilized peptides derived from spliced fibronectin type III repeat D of human tenascin-C significantly enhance neuronal attachment, neurite generation and neurite extension in a range of cell types (Ahmed, Liu et al. 2006). Therefore, surface immobilization of these small molecules that are neuroactive can provide a great advantage for neural tissue engineering. In addition small molecules, growth factors such as brain-derived neurotrophic factor (Horne, Nisbet et al. 2009) and basic fibroblast growth factor (Patel, Kurpinski et al. 2007) that are immobilized can also promote cell survival and neurite outgrowth.

Although electrospun nanofibers have gained widespread use in neural tissue engineering and will undoubtedly continue to do so in the future, "bottom up" or self-assembly approaches to nanofabrication have recently been applied to produce nanofibrous scaffolds for nerve repair. Although the number of studies in this area is currently not as numerous as that for electrospinning, this will perhaps change in the future as advances in the selfassembly processes lead to improved features such as mechanical properties and controlled degradability. The remainder of the chapter will focus on self-assembling oligopeptides and polypeptides, and provides a constructive counterpoint for the previous discussion on electrospun nanofibers.

\subsection{Lessons learned from nature: Self-assembling scaffolds}

Self-assembly is ubiquitous in nature and presents another approach for producing nanofibrous scaffolds for neural tissue engineering. Molecular self-assembly is mediated by weak, non-covalent bonds, such as van der Waals forces, hydrogen bonds, ionic bonds, and hydrophobic interactions. Although these bonds are relatively weak, collectively they play a major role in the conformation of biological molecules found in nature. In particular selfassembling peptides, under physiological conditions can give hydrogels with nanofibrous substructures. The self assembling peptides can be injected, potentially with replacement cells, at the lesion site in a minimally invasive procedure. 


\section{Self-assembled amphiphilic polymers (oligopeptides \& polypeptides)}

Amphiphilic peptide molecules, possessing a hydrophilic head group and a hydrophobic hydrocarbon tail group, can undergo micellization in aqueous environments. During this process, the hydrophobic interaction is the main driving force bringing closely together the head groups on the surface of the self-assembled aggregate. The self-assembled aggregate transition results from the balance between the attractive hydrophobic interactions and repulsive forces experienced by the head groups. Therefore, the self-assembly process can be triggered by the addition of cell culture medium in vitro or physiological fluids in vivo. Here the presence of ions in the culture medium or physiological fluids screen electrostatic repulsion among the molecules and promotes self-assembly (Silva, Czeisler et al. 2004; Tysseling-Mattiace, Sahni et al. 2008). Upon the addition of cell culture medium or physiological fluids, some oligopeptides form $\beta$-sheet secondary structures, followed by the spontaneous formation of nanofibrous structures with chain directions perpendicular to the fibril cross section (Zhang, Holmes et al. 1995; Holmes, de Lacalle et al. 2000; Semino, Kasahara et al. 2004; Gelain, Bottai et al. 2006). The self-assembly process yields a product with gel-like properties, while the micro-architecture of the self-assembled aggregate depends on the molecular structure and concentration of the amphiphiles, solvent dielectric constant, $\mathrm{pH}$, balance of counter ions, and type and concentration of salt. (Holmes, de Lacalle et al. 2000). The wormlike self-assembled aggregates with branched or randomly 3D network structures, normally have fiber cross-sectional diameters of 2-20 nm, and the apparent length can be as high as several micrometers (Cates and Candau 1990; Holmes, de Lacalle et al. 2000; Silva, Czeisler et al. 2004). In this chapter, the importance of nanofibrous structures via self-assembly that provide a 3D architecture for both endogenous and implanted cells will be highlighted.

The potential advantage of amphiphile molecular self-assembly is that the molecules can be injected into cavities within CNS/PNS lesion site which causes little tissue damage and minimal inflammation at the site of injection (Holmes, de Lacalle et al. 2000; TysselingMattiace, Sahni et al. 2008; Yang, Song et al. 2009), while larger injuries caused by implantation of other tissue engineering scaffolds like electrospun nanofibers may be difficult to avoid. Amphiphilic oligopeptides can be prepared in isotonic glucose solutions (Yang, Song et al. 2009) and then injected into the lesion site, where the self-assembly process is triggered by ions in the aqueous physiological environment.

The use of self-assembled nanofibers for nerve regeneration has provided some promising results, partially due to their high surface-to-volume ratio, fiber diameter and 3D architecture that resemble the natural ECM, but also in the spatial and high density presentation of small bioactive molecules to cell receptors. Self-assembled oligopeptide nanofibers present a promising microenvironment to cells with improved regenerative outcomes, including extensive neurite outgrowth, formation of functional synaptic connections for both cultured neuronal cell lines and primary neuronal cells, with no significant difference compared with cells cultured in vitro on Matrigel (Holmes, de Lacalle et al. 2000). Despite the simple chemistry of many of these oligopeptides (Holmes, de Lacalle et al. 2000; Guo, Su et al. 2007), compared with Matrigel which contains a range of ECM components and growth factors that are well known to promote neuronal cell adhesion and functional development, the structural roles of self-assembled nanofibrous scaffolds have 
shown a complimentary effect to chemical cues. Specific amino acid sequences such as arginine-glycine-aspartic acid (RGD) and isolucine-lysine-valine-alanine-valine (IKVAV) derived from fibronectin and laminin respectively, are involved in receptor interactions which play an important role in neurite outgrowth and guidance of neurite extension (Tashiro, Sephel et al. 1991; Schense, Bloch et al. 2000). These amino acid sequences can also be appended with synthetic peptides for self-assembly to create more biomimetic microenvironments.

Potentially, low cost amphiphilic polymers can be used as a backbone appended with these various chemical and biological motifs, able to self-assemble into 3D nanofibrous scaffolds and trigger specific cellular responses (Fig. 6) (Silva, Czeisler et al. 2004; Gelain, Bottai et al. 2006) Moreover, nanofibrous scaffolds tailored with well defined, synthetic functional groups such as cell signalling motifs known to control specific gene expression or cell signalling processes provide research tools to investigate cellular response in a more in vivo like 3D environment where cells are more likely to receive more external stimuli rather than traditional 2D surfaces coated with these functional groups.

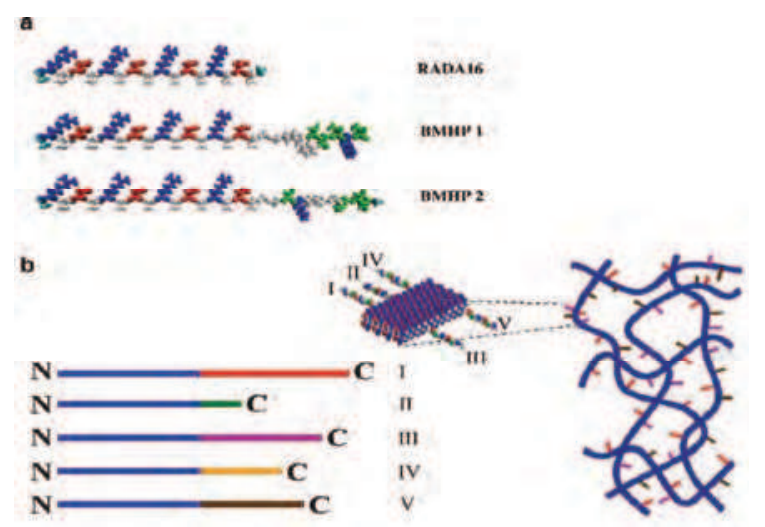

Fig. 6. (a) Schematic molecular structures of Arginine-Alanine-Aspartate (RAD) 16 peptide and Bone Marrow Homing Peptide (BMHP) 1, 2 appended RAD16. (b) Schematic structures of four different appended functional motifs RAD16 (I-V) and the structure of selfassembled peptide nanofibers. The enlarged insert shows the $\beta$-sheet with functional motifs extending out. (Reprinted from PLoS ONE with permission of Gelain et al.) (Gelain, Bottai et al. 2006).

Self-assembled oligopeptide nanofibers not only present these molecules to cells but arrange them in a spatial order that significantly changes the cellular response (Silva, Czeisler et al. 2004; Gelain, Bottai et al. 2006). For example, peptides coupled with IKVAV that selfassembled into nanofibers suppressed the differentiation of neural progenitor cells into astrocytes in vitro, however, non-bioactive IKVAV nanofibers mixed with soluble bioactive ones did not provide a biased differentiation effect (Silva, Czeisler et al. 2004). Selfassembled oligopeptides in vivo normally elicit a minimal inflammatory response (Guo, Su et al. 2007; Tysseling-Mattiace, Sahni et al. 2008). They can also suppress the hyperplastic response post CNS injury, but do not affect the early hypertrophic response, which may 
promote blood-brain barrier repair (Faulkner, Herrmann et al. 2004; Tysseling-Mattiace, Sahni et al. 2008). The reduced apoptosis of oligodendrocytes post injury within selfassembled oligopeptides can potentially contribute to the remyelination of regenerating axons at the injury site (Karimi-Abdolrezaee, Eftekharpour et al. 2006).

Diblock copolypeptides (about 200 amino acid residues) can also self assemble into nanofibrous hydrogels. The copolypeptides contain a hydrophilic polyelectrolyte block and a hydrophobic a-helical domain (Nowak, Breedveld et al. 2002; Breedveld, Nowak et al. 2004; Deming 2005) (Fig. 7). The polyelectrolyte block can be composed of a series of bioactive peptides like polylysine and polyglutamate with controlled degrees of polymerization which subsequently influences the gel point and strength of the resultant nanofibrous hydrogels in vitro and in vivo (Breedveld, Nowak et al. 2004; Yang, Song et al. 2009). The combination of hydrophobic a-helical block composed with a sufficient number of peptides residuals and the hydrophilic block helps the formation of a stiff gel and gelation at very low polypeptide concentrations (Nowak, Breedveld et al. 2002), potentially providing a wider range of hydrogel porosities. However, the properties of the hydrogel in vitro may not directly translate to hydrogels in vivo, due to the effect of different ions of body fluid on the self-assembly process (Beniash, Hartgerink et al. 2005). Unlike selfassembled oligopeptides, polypeptides can be assembled in vitro with or without cell suspensions, then injected to the lesion site by a micro-syringe due to shear thinning, followed by rapid structural recovery.

(a)

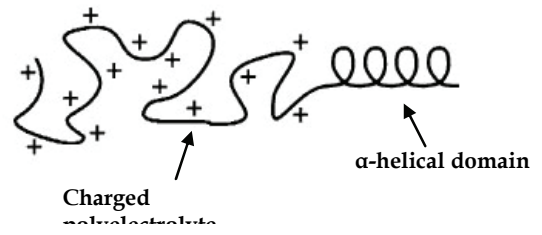

(b)
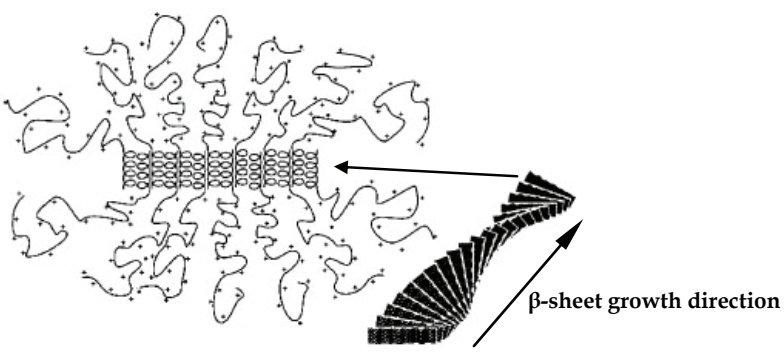

Fig. 7. Schematic structure of self-assembled polypeptides (a) Building block of selfassembled polypeptides, composed of charged polyelectrolyte block and oligopeptides that forms an a-helical domain. (b) Schematic structure of fibril-like nanostructure formed via $\beta$ sheet growth (no side chain shown). The enlarged insert shows the structure of $\beta$-sheet with polyelectrolyte side chains (Reprinted with permission from Breedveld et al. Copyright 2009 American Chemical Society) (Breedveld, Nowak et al. 2004). 
Self-assembled peptide nanofibers can potentially reduce the formation of a glial scar by means of either suppressing the astrogliosis post injury within the self-assembled scaffold due to the nanofiber dimension and surface chemistry (Tysseling-Mattiace, Sahni et al. 2008) or by preventing infiltration of glial cells into the hydogel which can last for up to 8 weeks (Yang, Song et al. 2009). Fig. 8 shows an example of injecting self-assembling lysine-leucine block co-polymer $\left(\mathrm{K}_{180} \mathrm{~L}_{20}\right)$ into the mouse forebrain, which triggered moderate astrogliosis comparable to saline injection controls. The astrocyte activity reduced remarkably after 8 weeks within the host tissue with no evidence of glial cell ingrowth into the self-assembled scaffold. The minimal inflammatory response of the host tissue (Holmes, de Lacalle et al. 2000; Yang, Song et al. 2009) to self-assembled peptides reveals the potential to reduce inflammation-induced secondary injuries as well as the level of inhibitory molecules to promote functional recovery for the PNS/CNS.
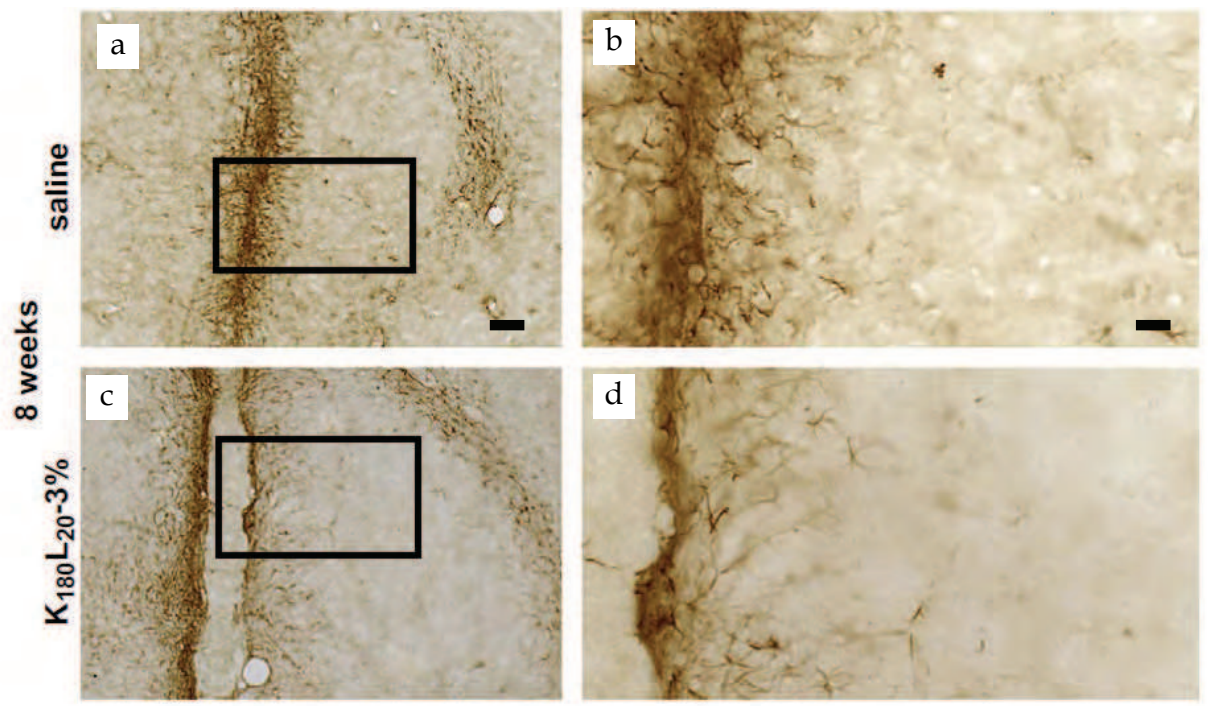

Fig. 8. Astrogliosis examined 8 weeks after physiological saline $(a, b)$ and $3 \% \mathrm{~K}_{180} \mathrm{~L}_{20}$ selfassembly polypeptide (c, d) injection into mouse forebrain. All tissue sections were immunochemically stained with GFAP for astrocytes. (b, d) are corresponding enlarged images of the box section in (a, c). Scale bar indicates $150 \mu \mathrm{m}$ in $(\mathrm{a}, \mathrm{c})$ and $45 \mu \mathrm{m}$ in $(\mathrm{b}, \mathrm{d})$ respectively. (Reprinted from Biomaterials with permission from Elsevier) (Yang, Song et al. 2009)

\section{Long term view on neural tissue engineering}

Although both electrospun and self-assembled peptide fibrous scaffolds show promising results in nerve regeneration after PNS/CNS injuries, there is still an essential requirement to further investigate the cellular response in vivo with scaffolds. The importance of transplantation of stem/progenitor cells arises because of the complicated dynamic in vivo microenvironment. The presence of proteins with non-specific adsorption properties on the scaffold surface can possibly cause unexpected outcomes in vivo (Yang, Song et al. 2009). 
This may lead to differences in cellular responses such as adhesion and differentiation. Besides, various types of resident cells presented at the lesion site such as endogenous astrocytes, oligodendrocytes, and microglia together with their molecular products post injury may contribute to a more pernicious environment to neurons and implanted cells. In the case of SCI, the state of the axons as well as the extent and chronicity of the lesions are an important determinant of locomotor ability, e.g. the time point at which transplanted oligodendrocytes remyelinate regenerating axons most effectively (Keirstead, Nistor et al. 2005). There is an urgent need to define at which stage of differentiation neural-committed progenitor cells should be transplanted, and therefore optimize the regenerative functions of transplanted cells.

An understanding of the mechanisms of the inhibitory environment and barriers for regeneration post PNS/CNS injury is still limited. Although many inhibitory factors, like chondroitin sulphate proteoglycans and axon outgrowth inhibitors have been identified, a large number of molecules that are being produced by various cell types post injury, have not yet been characterized and their role in nerve regeneration remains to be defined (Fitch and Silver 2008). Moreover, the specific stimuli that trigger astrocyte and oligodendroctye activation remains unclear, which restricts the use of these as support cells.

The current "design rules" of tissue engineering scaffolds used for nerve repair only mimic a small part of the structural features of natural ECM and incorporate a limited number of biochemical cues that are known to promote functional recovery of injured nerves. The inflammation and foreign body response due to the introduction of the scaffold and transplanted cells needs to be controlled to reduce further activation of cells like microglia, astrocytes and oligodendrocytes which contribute to the inhibitory environment. Studies using scaffolds with/without transplanted cells for nerve regeneration are largely based on animal models. However, in vivo studies in patients will be essential to evaluate the effectiveness of such neural tissue engineering approaches as therapeutic strategies.

There are still numerous physical and biochemical features (and combinations thereof) which remain uncharacterized, and may be of great importance for cell survival and regulation of the cellular response. For instance in vitro studies have revealed some of the cellular responses to specific physical or biochemical cues presented by the scaffold. However a detailed understanding of the cellular response to the combination of these external cues within 3D architectures is limited at this stage.

Many challenges lay ahead to achieve successful nerve regeneration using scaffolds. The current regenerative outcome obtained both in vitro and in vivo in animal models using nanostructured scaffolds, reveals the exciting possibility of manipulating cell behaviour that can promote cell survival, neurite outgrowth, appropriate reinnervation and consequently the functional recovery post PNS/CNS injuries. 


\section{Acknowledgements}

This work is supported by grants from the the Australian Research Council (DP0985433) the Baker Foundation, Bellberry Ltd, the National Health and Medical Research Council of Australia and the National Multiple Sclerosis Society of New York.

\section{References}

Access Economics (2009). Spinal Cord Injury Facts and Figures at a Glance. Birmingham, Alabama, National Spinal Cord Injury Statistical Center.

Ahmed, I., H.-Y. Liu, et al. (2006). "Three-dimensional nanofibrillar surfaces covalently modified with tenascin-C-derived peptides enhance neuronal growth in vitro." Journal of Biomedical Materials Research Part A 76A(4): 851-860.

Ao, Q., A. J. Wang, et al. (2007). "Combined transplantation of neural stem cells and olfactory ensheathing cells for the repair of spinal cord injuries." Medical Hypotheses 69(6): 1234-1237.

Bain, G., D. Kitchens, et al. (1995). "Embryonic stem cells express neuronal properties in vitro." Developmental Biology 168(2): 342-357.

Baker, B. M., A. O. Gee, et al. (2008). "The potential to improve cell infiltration in composite fiber-aligned electrospun scaffolds by the selective removal of sacrificial fibers." Biomaterials 29(15): 2348-2358.

Belle, J. E. L., M. A. Caldwell, et al. (2004). "Improving the survival of human CNS precursor-derived neurons after transplantation." Journal of Neuroscience Research 76(2): 174-183.

Beniash, E., J. D. Hartgerink, et al. (2005). "Self-assembling peptide amphiphile nanofiber matrices for cell entrapment." Acta Biomaterialia 1(4): 387-397.

Blight, A. R. (1994). "Effects of silica on the outcome from experimental spinal cord injury: Implication of macrophages in secondary tissue damage." Neuroscience 60(1): 263273.

Borkenhagen, M., R. C. Stoll, et al. (1998). "In vivo performance of a new biodegradable polyester urethane system used as a nerve guidance channel." Biomaterials 19(23): 2155-2165.

Boudriot, U. and R. D. A. G. J. H. Wendorff (2006). "Electrospinning Approaches Toward Scaffold Engineering: A Brief Overview." Artificial Organs 30(10): 785-792.

Breedveld, V., A. P. Nowak, et al. (2004). "Rheology of block copolypeptide solutions: hydrogels with tunable properties." Macromolecules 37(10): 3943-3953.

Bundesen, L. Q., T. A. Scheel, et al. (2003). "Ephrin-B2 and EphB2 regulation of astrocytemeningeal fibroblast interactions in response to spinal cord lesions in adult rats." Journal of neuroscience 23(21): 7789-7800.

Busch, S. A. and J. Silver (2007). "The role of extracellular matrix in CNS regeneration." Current Opinion in Neurobiology 17(1): 120-127.

Carlberg, B., M. Z. Axell, et al. (2009). "Electrospun polyurethane scaffolds for proliferation and neuronal differentiation of human embryonic stem cells." Biomedical Materials 4(4): 045004.

Cates, M. E. and S. J. Candau (1990). "Statics and dynamics of worm-like surfactant micelles." Journal of Physics: Condensed Matter 2(33): 6869-6892. 
Cecchini, M., G. Bumma, et al. (2007). "PC12 differentiation on biopolymer nanostructures." Nanotechnology 18(50): 505103.

Chamberlain, L. J., I. V. Yannas, et al. (1998). "Early peripheral nerve healing in collagen and silicone tube implants: Myofibroblasts and the cellular response." Biomaterials 19(15): 1393-1403.

Chan, C. C. M., C. R. Roberts, et al. (2008). "Aggrecan components differentially modulate nerve growth factor-responsive and neurotrophin-3-responsive dorsal root ganglion neurite growth." Journal of Neuroscience Research 86(3): 581-592.

Chen, Y.-S., C.-L. Hsieh, et al. (2000). "Peripheral nerve regeneration using silicone rubber chambers filled with collagen, laminin and fibronectin." Biomaterials 21(15): 15411547.

Chew, S. Y., R. Mi, et al. (2007). "Aligned protein-polymer composite fibers enhance nerve regeneration: a potential tissue-engineering platform." Advanced Functional Materials 17(8): 1288-1296.

Christopherson, G. T., H. Song, et al. (2009). "The influence of fiber diameter of electrospun substrates on neural stem cell differentiation and proliferation." Biomaterials 30(4): 556-564.

Corey, J. M., D. Y. Lin, et al. (2007). "Aligned electrospun nanofibers specify the direction of dorsal root ganglia neurite growth." Journal of Biomedical Materials Research Part A 83A(3): 636-645.

Cummings, B. J., N. Uchida, et al. (2006). "Human neural stem cell differentiation following transplantation into spinal cord injured mice: association with recovery of locomotor function." Neurological Research 28(5): 474-481.

David, S. and A. J. Aguayo (1981). "Axonal elongation into peripheral nervous system "bridges" after central nervous system injury in adult rats." Science 214(4523): 931933.

Deming, T. J. (2005). "Polypeptide hydrogels via a unique assembly mechanism." Soft Matter 1: 28-35.

Desai, T. A. (2000). "Micro- and nanoscale structures for tissue engineering constructs." Medical Engineering \& Physics 22(9): 595-606.

Deshpande, D. M., Y.-S. Kim, et al. (2006). "Recovery from paralysis in adult rats using embryonic stem cells." Annals of Neurology 60(1): 32-44.

Dirnagl, U., C. Iadecola, et al. (1999). "Pathobiology of ischaemic stroke: an integrated view." Trends in Neurosciences 22(9): 391-397.

Dodla, M. C. and R. V. Bellamkonda (2008). "Differences between the effect of anisotropic and isotropic laminin and nerve growth factor presenting scaffolds on nerve regeneration across long peripheral nerve gaps." Biomaterials 29(1): 33-46.

Dong, B., O. Arnoult, et al. (2009). "Electrospinning of collagen nanofiber scaffolds from benign solvents." Macromolecular Rapid Communications 30(7): 539-542.

Economics, A. (2009). The economic cost of spinal cord injury and traumatic brain injury in Australia, Access Economics for the Victorian Neurotrauma Initiative.

Eichhorn, S. J. and W. W. Sampson (2005). "Statistical geometry of pores and statistics of porous nanofibrous assemblies." Journal of the royal society Interface 2: 309-318.

Fan, Y. W., F. Z. Cui, et al. (2002). "Culture of neural cells on silicon wafers with nano-scale surface topograph." Journal of Neuroscience Methods 120(1): 17-23. 
Faulkner, J. R., J. E. Herrmann, et al. (2004). "Reactive astrocytes protect tissue and preserve function after spinal cord injury." Journal of Neuroscience 24(9): 2143-2155.

Fawcett, J. W. (1997). "Astrocytic and neuronal factors affecting axon regeneration in the damaged central nervous system." Cell and Tissue Research 290(2):371-377.

Ferrari, A., M. Cecchini, et al. (2009). "Directional PC12 cell migration along plastic nanotracks." IEEE Transactions on Biomedical Engineering 56: 2692-2696.

Fidler, P. S., K. Schuette, et al. (1999). "Comparing astrocytic cell lines that are inhibitory or permissive for axon growth: the major axon-inhibitory proteoglycan is NG2." Journal of Neuroscience 19(20): 8778-8788.

Filbin, M. T. (2003). "Myelin-associated inhibitors of axonal regeneration in the adult mammalian CNS." Nature Reviews Neuroscience 4(9): 703-713.

Fitch, M. T., C. Doller, et al. (1999). "Cellular and molecular mechanisms of glial scarring and progressive cavitation: in vivo and in vitro analysis of inflammation-induced secondary injury after CNS trauma." Journal of Neuroscience 19(19): 8182-8198.

Fitch, M. T. and J. Silver (2008). "CNS injury, glial scars, and inflammation: Inhibitory extracellular matrices and regeneration failure." Experimental Neurology 209(2): 294-301.

Foley, J. D., E. W. Grunwald, et al. (2005). "Cooperative modulation of neuritogenesis by PC12 cells by topography and nerve growth factor." Biomaterials 26(17): 3639-3644.

Formhals, A. (1934). Process and apparatus for preparing artificial threads. 1975504.

Geiger, B., A. Bershadsky, et al. (2001). "Transmembrane crosstalk between the extracellular matrix and the cytoskeleton." Nature Reviews. Molecular Cell Biology 2(11): 793805.

Gelain, F., D. Bottai, et al. (2006). "Designer self-assembling peptide nanofiber scaffolds for adult mouse neural stem cell 3-dimensional cultures." PLoS ONE 1(1): e119.

Gerecht, S., C. J. Bettinger, et al. (2007). "The effect of actin disrupting agents on contact guidance of human embryonic stem cells." Biomaterials 28(28): 4068-4077.

GrandPre, T., F. Nakamura, et al. (2000). "Identification of the Nogo inhibitor of axon regeneration as a Reticulon protein." Nature 403(6768): 439-444.

Guo, J., H. Su, et al. (2007). "Reknitting the injured spinal cord by self-assembling peptide nanofiber scaffold." Nanomedicine: Nanotechnology, Biology and Medicine 3(4): 311-321.

Gupta, D., J. Venugopal, et al. (2009). "Aligned and random nanofibrous substrate for the in vitro culture of Schwann cells for neural tissue engineering." Acta Biomaterialia 5(7): 2560-2569.

He, Z. and V. Koprivica (2004). "The Nogo signaling pathway for regeneration block." Annual Review of Neuroscience 27(1): 341-368.

Heijke, G. C. M., P. J. Klopper, et al. (2001). "Silicone rubber tubulization in peripheral sensory nerve reconstruction: An experimental study in rabbits." Microsurgery 21(7): 306-316.

Holmes, T. C., S. de Lacalle, et al. (2000). "Extensive neurite outgrowth and active synapse formation on self-assembling peptide scaffolds." Proceedings of the National Academy of Sciences of the United States of America 97(12): 6728-6733.

Horne, M. K., D. R. Nisbet, et al. (2009). "Three dimensional nanofibrous scaffolds incorporating immobilized BDNF promote proliferation and differentiation of cortical neural stem cells." Stem Cells and Development. accepted 
Ichihara, S., Y. Inada, et al. (2009). "Development of new nerve guide tube for repair of long nerve defects." Tissue Engineering Part C: Methods 15(3): 387-402.

Jansen, K., J. F. A. van der Werff, et al. (2004). "A hyaluronan-based nerve guide: in vitro cytotoxicity, subcutaneous tissue reactions, and degradation in the rat." Biomaterials 25(3): 483-489.

Ji, Y., K. Ghosh, et al. (2006). "Electrospun three-dimensional hyaluronic acid nanofibrous scaffolds." Biomaterials 27(20): 3782-3792.

Jose, M. V., V. Thomas, et al. (2009). "Fabrication and characterization of aligned nanofibrous PLGA/Collagen blends as bone tissue scaffolds." Polymer 50(15): 3778-3785.

Karimi-Abdolrezaee, S., E. Eftekharpour, et al. (2006). "Delayed transplantation of adult neural precursor cells promotes remyelination and functional neurological recovery after spinal cord injury." Journal of Neuroscience 26(13): 3377-3389.

Karnezis, T., W. Mandemakers, et al. (2004). "The neurite outgrowth inhibitor Nogo A is involved in autoimmune-mediated demyelination." Nature Neuroscience 7: 736744 .

Keirstead, H. S., G. Nistor, et al. (2005). "Human embryonic stem cell-derived oligodendrocyte progenitor cell transplants remyelinate and restore locomotion after spinal cord injury." Journal of Neuroscience 25(19): 4694-4705.

Khan, T., S. Sayers, et al. (1990). "Carbon filaments provide support and directionality to growing rat fetal spinal cord explants." Neuroscience Letters 118(2): 172-176.

Kim, H. S., K. Kim, et al. (2005). "Morphological characterization of electrospun nano-fibrous membranes of biodegradable poly(L-lactide) and poly(lactide-co-glycolide)." Macromolecular Symposia 224(1): 145-154.

Kim, Y.-t., V. K. Haftel, et al. (2008). "The role of aligned polymer fiber-based constructs in the bridging of long peripheral nerve gaps." Biomaterials 29(21): 3117-3127.

Kitahara, A., Y. Suzuki, et al. (1998). "Evaluation of collagen nerve guide in facial nerve regeneration." Journal of Artificial Organs 1(1): 22-27.

Kottis, V., P. Thibault, et al. (2002). "Oligodendrocyte-myelin glycoprotein (OMgp) is an inhibitor of neurite outgrowth." Journal of Neurochemistry 82(6): 1566-1569.

Kwon, I. K. and T. Matsuda (2005). "Co-electrospun nanofiber fabrics of poly(l-lactide-co-ecaprolactone) with Type I collagen or heparin." Biomacromolecules 6(4): 2096-2105.

Labrador, R. O., M. But, et al. (1998). "Influence of collagen and laminin gels concentration on nerve regeneration after resection and tube repair." Experimental Neurology 149(1): 243-252.

Leaver, S. G., A. R. Harvey, et al. (2006). "Adult olfactory ensheathing glia promote the longdistance growth of adult retinal ganglion cell neurites in vitro." Glia 53(5): 467-476.

Lee, A. C., V. M. Yu, et al. (2003). "Controlled release of nerve growth factor enhances sciatic nerve regeneration." Experimental Neurology 184(1): 295-303.

Li, M. S. and S. David (1996). "Topical glucocorticoids modulate the lesion interface after cerebral cortical stab wounds in adult rats." Glia 18(4): 306-318.

Lietz, M., A. Ullrich, et al. (2006). "Physical and biological performance of a novel block copolymer nerve guide." Biotechnology and Bioengineering 93(1): 99-109.

Lu, P., L. L. Jones, et al. (2005). "BDNF-expressing marrow stromal cells support extensive axonal growth at sites of spinal cord injury." Experimental Neurology 191(2): 344360 . 
Lundborg, G., L. B. Dahlin, et al. (1991). "Ulnar nerve repair by the silicone chamber technique." Scandinavian Journal of Plastic and Reconstructive Surgery and Hand Surgery 25(1): 79 - 82.

Lundborg, G., L. B. Dahlin, et al. (1982). "Nerve regeneration in silicone chambers: Influence of gap length and of distal stump components." Experimental Neurology 76(2): 361375.

Lundborg, G., B. Rosen, et al. (2004). "Tubular repair of the median or ulnar nerve in the human forearm: A 5-year follow-up." Journal of hand surgery 29(2): 100-107.

Manwaring, M. E., J. F. Walsh, et al. (2004). "Contact guidance induced organization of extracellular matrix." Biomaterials 25(17): 3631-3638.

McDonald, J. W., D. Becker, et al. (2004). "Repair of the injured spinal cord and the potential of embryonic stem cell transplantation." Journal of Neurotrauma 21(4): 383-393.

Mingyu, C., G. Kai, et al. (2004). "Surface modification and characterization of chitosan film blended with poly-L-lysine." Journal of biomaterials applications 19(1): 59-75.

Moore, K., M. Macsween, et al. (2006). "Immobilized Concentration Gradients of Neurotrophic Factors Guide Neurite Outgrowth of Primary Neurons in Macroporous Scaffolds." Tissue engineering 12(2): 267-278.

Murakami, T., Y. Fujimoto, et al. (2003). "Transplanted neuronal progenitor cells in a peripheral nerve gap promote nerve repair." Brain Research 974(1-2): 17-24.

Nakamura, T., Y. Inada, et al. (2004). "Experimental study on the regeneration of peripheral nerve gaps through a polyglycolic acid-collagen (PGA-collagen) tube." Brain Research 1027(1-2): 18-29.

Nam, J., Y. Huang, et al. (2007). "Improved Cellular Infiltration in Electrospun Fiber via Engineered Porosity." Tissue engineering 13(9): 2249-2257.

National Spinal Cord Injury Statistical Center (2009). "Spinal Cord Injury Facts and Figures at a Glance". Birmingham, Alabama.

Neville, C. M., A. Y. Huang, et al. (2009). "Neural Precursor Cell Lines Promote Neurite Branching." International Journal of Neuroscience 119(1): 15-39.

Nisbet, D. R., L. M. Y. Yu, et al. (2008). "Characterization of neural stem cells on electrospun poly( $\varepsilon$-caprolactone) submicron scaffolds: evaluating their potential in neural tissue engineering." Journal of Biomaterials Science, Polymer Edition 19: 623-634.

Nowak, A. P., V. Breedveld, et al. (2002). "Rapidly recovering hydrogel scaffolds from selfassembling diblock copolypeptide amphiphiles." Nature 417(6887): 424-428.

Oh, S. H., J. H. Kim, et al. (2008). "Peripheral nerve regeneration within an asymmetrically porous PLGA/Pluronic F127 nerve guide conduit." Biomaterials 29(11): 1601-1609.

Okada, T., T. Hayashi, et al. (1992). "Degradation of collagen suture in vitro and in vivo." Biomaterials 13(7): 448-454.

Panseri, S., C. Cunha, et al. (2008). "Electrospun micro- and nanofiber tubes for functional nervous regeneration in sciatic nerve transections." BMC Biotechnology 8: 39.

Patel, M., P. J. Vandevord, et al. (2008). "Collagen--Chitosan Nerve Guides for Peripheral Nerve Repair: A Histomorphometric Study." Journal of Biomaterials Applications 23(2): 101-121.

Patel, S., K. Kurpinski, et al. (2007). "Bioactive Nanofibers: Synergistic Effects of Nanotopography and Chemical Signaling on Cell Guidance." Nano Letters 7(7): 2122-2128. 
Pham, P. Q., U. Sharma, et al. (2006). "Electrospinning of Polymeric Nanofibers for Tissue Engineering Applications: A Review." Tissue engineering 12(5): 1197-1211.

Schense, J. C., J. Bloch, et al. (2000). "Enzymatic incorporation of bioactive peptides into fibrin matrices enhances neurite extension." Nature Biotechnology 18(4): 415-419.

Schmidhammer, R., S. Zandieh, et al. (2005). "Effects of alleviated tension at the nerve repair site using biodegradable tubular conduits: Histological, electrophysiological and functional results in a rat model." European Surgery 37(4): 213-219.

Schmidt, C. E. and J. B. Leach (2003). "Neural Tissue Engineering: Strategies for Repair and Regeneration." Annual Review of Biomedical Engineering 5(1): 293-347.

Schnell, E., K. Klinkhammer, et al. (2007). "Guidance of glial cell migration and axonal growth on electrospun nanofibers of poly-e-caprolactone and a collagen/poly-ecaprolactone blend." Biomaterials 28(19): 3012-3025.

Semino, C. E., J. Kasahara, et al. (2004). "Entrapment of Migrating Hippocampal Neural Cells in Three-Dimensional Peptide Nanofiber Scaffold." Tissue engineering 10(34): 643-655.

Silva, G. A., C. Czeisler, et al. (2004). "Selective Differentiation of Neural Progenitor Cells by High-Epitope Density Nanofibers." Science 303(5662): 1352-1355.

Sinis, N., H.-E. Schaller, et al. (2009). "Nerve regeneration across a 2-cm gap in the rat median nerve using a resorbable nerve conduit filled with Schwann cells." Journal of Neurosurgery 103(6): 1067-1076.

Smeal, R., R. Rabbitt, et al. (2005). "Substrate Curvature Influences the Direction of Nerve Outgrowth." Annals of Biomedical Engineering 33(3): 376-382.

Stevens, M. M. and J. H. George (2005). "Exploring and Engineering the Cell Surface Interface." Science 310(5751): 1135-1138.

Tashiro, K.-I., G. C. Sephel, et al. (1991). "The RGD containing site of the mouse laminin A chain is active for cell attachment, spreading, migration and neurite outgrowth." Journal of Cellular Physiology 146(3): 451-459.

Taylor, G. (1969). "Electrically Driven Jets." Proceedings of the Royal Society of London. Series A, Mathematical and Physical Sciences 313(1515): 453-475.

Taylor, J., P. Pesheva, et al. (1993). "Influence of janusin and tenascin on growth cone behavior in vitro." Journal of Neuroscience Research 35(4): 347-362.

Terzis, J., B. Faibisoff, et al. (1975). "The Nerve Gap: Suture Under Tension Vs. Graft." Plastic and Reconstructive Surgery 56(2): 166-170.

Tom, V. J., M. P. Steinmetz, et al. (2004). "Studies on the Development and Behavior of the Dystrophic Growth Cone, the Hallmark of Regeneration Failure, in an In Vitro Model of the Glial Scar and after Spinal Cord Injury." The Journal of Neuroscience 24(29): 6531-6539.

Tsai, E. C., P. D. Dalton, et al. (2004). "Synthetic Hydrogel Guidance Channels Facilitate Regeneration of Adult Rat Brainstem Motor Axons after Complete Spinal Cord Transection." Journal of Neurotrauma 21(6): 789-804.

Tysseling-Mattiace, V. M., V. Sahni, et al. (2008). "Self-Assembling Nanofibers Inhibit Glial Scar Formation and Promote Axon Elongation after Spinal Cord Injury." The Journal of Neuroscience 28(14): 3814-3823. 
Wen, X. and P. A. Tresco (2006). "Effect of filament diameter and extracellular matrix molecule precoating on neurite outgrowth and Schwann cell behavior on multifilament entubulation bridging device in vitro." Journal of Biomedical Materials Research, Part A 76(3): 626-637.

Xie, F., Q. F. Li, et al. (2008). "In vitro and in vivo evaluation of a biodegradable chitosanPLA composite peripheral nerve guide conduit material." Microsurgery 28(6): 471479.

Xie, J., S. M. Willerth, et al. (2009). "The differentiation of embryonic stem cells seeded on electrospun nanofibers into neural lineages." Biomaterials 30(3): 354-362.

Yang, C.-Y., B. Song, et al. (2009). "Biocompatibility of amphiphilic diblock copolypeptide hydrogels in the central nervous system." Biomaterials 30(15): 2881-2898.

Yang, F., C. Y. Xu, et al. (2004). "Characterization of neural stem cells on electrospun poly(Llactic acid) nanofibrous scaffold." Journal of Biomaterials Science, Polymer Edition 15(12): 1483-1497.

Yao, L., N. O'Brien, et al. (2009). "Orienting neurite growth in electrospun fibrous neural conduits." Journal of Biomedical Materials Research Part B: Applied Biomaterials 90B(2): 483-491.

Zeugolis, D. I., S. T. Khew, et al. (2008). "Electro-spinning of pure collagen nano-fibres - Just an expensive way to make gelatin?" Biomaterials 29(15): 2293-2305.

Zhang, H., K. Uchimura, et al. (2006). "Brain keratan sulfate and glial scar formation." Annals of the New York Academy of Sciences 1086(Integrated Molecular Medicine for Neuronal and Neoplastic Disorders): 81-90.

Zhang, S., T. C. Holmes, et al. (1995). "Self-complementary oligopeptide matrices support mammalian cell attachment." Biomaterials 16(18): 1385-1393.

Zhao, Q., G. Lundborg, et al. (1997). "Nerve regeneration in a 'pseudo-nerve' graft created in a silicone tube." Brain Research 769(1): 125-134.

Zhu, X., W. Cui, et al. (2008). "Electrospun Fibrous Mats with High Porosity as Potential Scaffolds for Skin Tissue Engineering." Biomacromolecules 9(7): 1795-1801.

Zong, X., K. Kim, et al. (2002). "Structure and process relationship of electrospun bioabsorbable nanofiber membranes." Polymer 43(16): 4403-4412. 


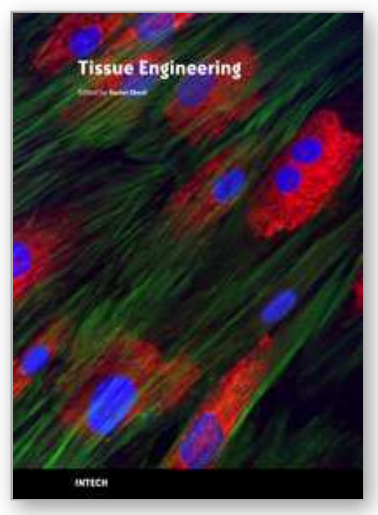

\author{
Tissue Engineering \\ Edited by Daniel Eberli
}

ISBN 978-953-307-079-7

Hard cover, 524 pages

Publisher InTech

Published online 01, March, 2010

Published in print edition March, 2010

The Tissue Engineering approach has major advantages over traditional organ transplantation and circumvents the problem of organ shortage. Tissues that closely match the patient's needs can be reconstructed from readily available biopsies and subsequently be implanted with minimal or no immunogenicity. This eventually conquers several limitations encountered in tissue transplantation approaches. This book serves as a good starting point for anyone interested in the application of Tissue Engineering. It offers a colorful mix of topics, which explain the obstacles and possible solutions for TE applications.

\title{
How to reference
}

In order to correctly reference this scholarly work, feel free to copy and paste the following:

Kun Zhou, David Nisbet, George Thouas, Claude Bernard and John Forsythe (2010). Bio-nanotechnology Approaches to Neural Tissue Engineering, Tissue Engineering, Daniel Eberli (Ed.), ISBN: 978-953-307-079-7, InTech, Available from: http://www.intechopen.com/books/tissue-engineering/bio-nanotechnology-approachesto-neural-tissue-engineering

\section{INTECH}

open science | open minds

\section{InTech Europe}

University Campus STeP Ri Slavka Krautzeka 83/A

51000 Rijeka, Croatia

Phone: +385 (51) 770447

Fax: +385 (51) 686166

www.intechopen.com

\section{InTech China}

Unit 405, Office Block, Hotel Equatorial Shanghai

No.65, Yan An Road (West), Shanghai, 200040, China

中国上海市延安西路65号上海国际贵都大饭店办公楼405单元

Phone: +86-21-62489820

Fax: +86-21-62489821 
(C) 2010 The Author(s). Licensee IntechOpen. This chapter is distributed under the terms of the Creative Commons Attribution-NonCommercialShareAlike-3.0 License, which permits use, distribution and reproduction for non-commercial purposes, provided the original is properly cited and derivative works building on this content are distributed under the same license. 